\title{
Responses of Transgenic Tobacco Plants with Increased Proline Content to Drought and/or Heat Stress
}

\author{
Jana Pospisilova ${ }^{*}$, Daniel Haisel ${ }^{1}$, Radomira Vankova ${ }^{2}$ \\ ${ }^{1}$ Institute of Experimental Botany, Academy of Sciences of the Czech Republic, Na Karlovce, Prague, Czech Republic; ${ }^{2}$ Institute of \\ Experimental Botany, Academy of Sciences of the Czech Republic, Rozvojová, Prague, Czech Republic. \\ Email: " pospisilova@ueb.cas.cz
}

Received March 28 $8^{\text {th }}, 2011$; revised May $3^{\text {rd }}, 2011$; accepted May $11^{\text {th }}, 2011$.

\begin{abstract}
Transgenic tobacco plants (M51-1) constitutively over-expressing a modified gene for the proline biosynthetic enzyme $\Delta^{2}$-pyrroline-5-carboxylate synthetase (P5CSF129A) and the corresponding wild-type plants (WT) were compared during drought or heat stress and under combination of both stresses. The proline content in M51-1 was several times higher than in WT plants. Under optimal conditions, the transpiration rate and stomatal conductance of M51-1 plants were lower than those in WT plants. The differences in net photosynthetic rate were not significant and water use efficiency and contents of chlorophyll and xanthophyll cycle pigments were higher in M51-1 than in WT plants. Drought induced by cessation of watering for $7 d$ resulted in decrease of all gas exchange parameters and chlorophyll content, but in an increase of the content of xanthophyll cycle pigments and degree of their de-epoxidation. After application of heat stress $\left(40^{\circ} \mathrm{C} / 60 \mathrm{~min}\right)$ to control or water-stressed plants the gas exchange parameters decreased considerably. Short-term heat stress alone, however, did not affect pigment contents. The responses of M51-1 and WT plants to the tested stresses did not differ significantly. Therefore, a decisive contribution of elevated proline content to drought or heat stress tolerance of tobacco was not proved.
\end{abstract}

Keywords: Carotenoids, Chlorophyll, Net Photosynthetic Rate, Stomatal Conductance, Transpiration Rate, Xanthophyll Cycle Pigments

\section{Introduction}

In many plant species, osmotic adjustment (lowering of the osmotic potential in order to maintain the pressure potential) occurs in response to water stress induced by drought, salinity or low temperature. The composition of solutes contributing to osmotic adjustment differs according to the plant species or genotype, duration as well as severity of water stress $[1,2]$. One of the well-known osmotically active compounds is proline (for review see e.g. [3]). It may serve not only as osmoprotectant, but also as a molecular chaperone, antioxidant, regulator of redox homeostasis or source of carbon and nitrogen (for review see [4]). Therefore, its accumulation occurs not only under water stress but also under other abiotic and biotic stresses.

In higher plants, proline is synthesized mainly from glutamate. The oxidation of glutamate to glutamic- $\gamma$-semialdehyde (GSA) is catalysed by a $\Delta^{1}$-pyrroline-5-car- boxylate synthetase (P5CS). GSA undergoes spontaneous cycling to $\Delta^{1}$-pyrroline 5-carboxylate (P5C). The next step involves the reduction of P5C to proline by $\Delta^{1}$-pyrroline5-carboxylate reductase (P5CR). Proline biosynthesis steadily occurs in the cytosol, while it is augmented to the chloroplasts during stress conditions [4]. As proline biosynthesis requires NADPH, the enhanced rate of its biosynthesis in chloroplasts maintains the low NADPH: $\mathrm{NADP}^{+}$ratio, resulting in reduction of photoinhibition under high irradiance [5]. Thippeswamy et al. [6] suggested that the proline synthesis from glutamate has been limited by P5CS activity. Proline degradation by proline dehydrogenase (PHD) occurs in mitochondria [4]. Intracellular proline content thus depends on its biosynthesis, degradation and transport from other plant parts [7]. For example, P5CS activity in Arabis stelleri was increased by mannitol and sorbitol, but not by $\mathrm{NaCl}$, while activity of PHD was decreased by mannitol and $\mathrm{NaCl}$, which resulted in an increase of free proline amount under all, 
above mentioned, treatments [8]. During stress conditions, elevation of proline content coincided with modulation of the enzyme activities (increase in case of P5CR and decrease in PDH, respectively), as well as with changes in expression of the corresponding genes $[6,9,10]$. Recently, two closely related genes, P5CS1 and P5CS2, were identified in Arabidopsis [11]. The former one is involved in regulation of development, while the latter one is stress-responsible [4]. Similarly, two genes for proline degradation, $M S P H D 1$ and $M S P H D 2$ were distinguished in Medicago sativa [9].

The correlation between proline accumulation and plant stress tolerance is not always clear (for review see $[4,12])$. For example, with increased $\mathrm{NaCl}$ concentration, salt resistant rice cultivars accumulated less proline than the salt sensitive ones [13]. With the aim to contribute to the elucidation of the role of proline in response to drought and heat stress alone or in combination, transgenic tobacco plants (M51-1) constitutively over-expressing a modified gene (P5CSF129A) for the proline biosynthetic enzyme $\Delta^{2}$-pyrroline-5-carboxylate synthetase and the corresponding wild-type plants (WT) were compared. While previous papers focused on M51-1 plants described predominantly proline and phytohormone contents $[14,15]$, in the present paper net photosynthetic rate, transpiration rate, stomatal conductance and pigment contents were followed.

\section{Materials and Methods}

\subsection{Plants and Cultivation}

The seeds of transgenic tobacco plants were kindly donated by Dr. Jozef Gubis. The transformation was described in detail by Gubis et al. [14]. Wild type (WT) and transgenic (M51-1) tobacco (Nicotiana tabacum L.) seedlings were grown in Perlite with nutrient solution in a growth chamber at a 16-h photoperiod, an irradiance of $250 \mu \mathrm{mol}$ (photon) $\mathrm{m}^{-2} \cdot \mathrm{s}^{-1}(400-700 \mathrm{~nm})$, day/night temperature of $25^{\circ} \mathrm{C} / 20^{\circ} \mathrm{C}$, and relative humidity of about $50 \%$. The below mentioned parameters were followed in control plants sufficiently supplied with water, after cessation of watering for 7 days and again after rehydration for 7 days. Heat shock $\left(40^{\circ} \mathrm{C}, 60 \mathrm{~min}\right)$ was applied either to control plants or to water-stressed plants and measurements were done immediately after treatment.

\subsection{Measurements of Gas Exchange and Photosynthetic Pigments}

Net photosynthetic rate $\left(\mathrm{P}_{\mathrm{N}}\right)$, transpiration rate $(\mathrm{E})$ and stomatal conductance $\left(\mathrm{g}_{\mathrm{s}}\right)$ were measured on attached leaves using the commercial gas exchange system $L C A-4$ (ADC Bio Scientific, Hoddesdon, UK). All measurement were done at a temperature of $25^{\circ} \mathrm{C}$, saturating irradiance of $750 \mu \mathrm{mol} \mathrm{m}{ }^{-2} \cdot \mathrm{s}^{-1}, \mathrm{CO}_{2}$ concentration of $350 \mu \mathrm{mol} \cdot \mathrm{mol}^{-1}$, and relative humidity of about $30 \%$. Contents of photosynthetic pigments were determined in acetone extracts of leaf discs by HPLC (ECOM, Prague, Czech Republic) using a reverse phase column (Watrex Nucleosil 120-5-C18, $5 \mu \mathrm{m}$ particle size, $125 \times 4 \mathrm{~mm}$ ). The solvent system was acetonitrile:methanol:water $(80: 12: 10)$ followed by methanol:ethylacetate (95:5), the gradient was run from 2 to $6 \mathrm{~min}$. The flow rate was $1 \mathrm{~cm}^{3} \cdot \mathrm{min}^{-1}$, the detection wavelength $445 \mathrm{~nm}$. The pigment analyses were performed using software Clarity (DataApex, Prague, Czech Republic). Contents of proline and abscisic acid were measured as described previously by Dobra et al. [14]

\subsection{Data Analysis}

Presented results are means \pm standard error of 9 (gas exchange) or 3 (pigments) independent samples. Significance of differences between WT and M51-1 as well as between control and treated plants was evaluated by $t$-test (Tables 1 and 2). The experiments were repeated twice with similar results.

\section{Results}

The characteristic feature of transgenic tobacco plants M51-1 was several times higher proline content in comparison with WT $[14,15]$. In both genotypes, prolonged water stress resulted in a highly significant increase in proline content (Figure 1), while no significant changes in proline content were observed after heat stress [15].

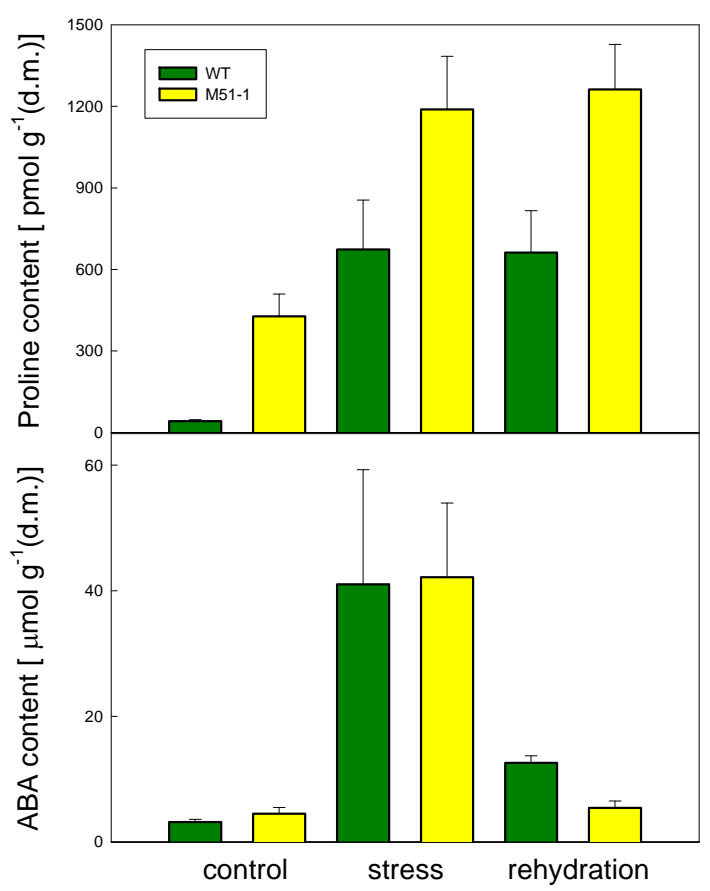

Figure 1. Contents of proline and abscisic acid in wild type (WT) and transgenic (M51-1) tobacco plants during water stress and rehydration (both lasted 7 days). 


\subsection{Comparison of Transgenic and Wild Type Plants under Sufficient Water Supply}

In non-stressed plants, transpiration rate $(\mathrm{E})$ and stomatal conductance $\left(\mathrm{g}_{\mathrm{s}}\right)$ of M51-1 were lower than those of WT, which was in agreement with higher abscisic acid content in M51-1 (Figure 1). Net photosynthetic rate $\left(\mathrm{P}_{\mathrm{N}}\right)$ was not significantly different between the plant types (Figure 2). Water use efficiency (WUE $\left.=\mathrm{P}_{\mathrm{N}} / \mathrm{E}\right)$ in M51-1 and WT plants was 5.95 and $5.08 \mathrm{mmol}\left(\mathrm{CO}_{2}\right) \mathrm{mol}^{-1}$ $\left(\mathrm{H}_{2} \mathrm{O}\right)$, respectively. Contents of chlorophyll $(\mathrm{Chl} a+b)$ or xanthophyll cycle pigments (Xan $=$ zeaxanthin + anteraxanthin + violaxanthin) were significantly higher in M51-1 than WT (Figure 3).

\subsection{Response of Transgenic and Wild Type Plants to Drought and Rehydration}

Cessation of watering for 7 days induced water stress and decreased $\mathrm{P}_{\mathrm{N}}, \mathrm{E}$ and $\mathrm{g}_{\mathrm{s}}$, the response being similar in M51-1 and WT plants. All gas exchange parameters were partially recovered after rehydration in both plant types (Figure 2). The water stress slightly decreased Chl $a+b$ content, similarly in both plant types. The content of Car was slightly increased under drought, this increase was higher in M51-1 than in wild type. The Xan content and the degree of their deepoxidation [DEPS $=$ zeaxanthin + 0.5 antheraxanthin)/(antheraxanthin + violaxanthin + zeaxanthin)] were markedly increased under drought in both plant types. These changes were partially reversed after rehydration (Figure 3).

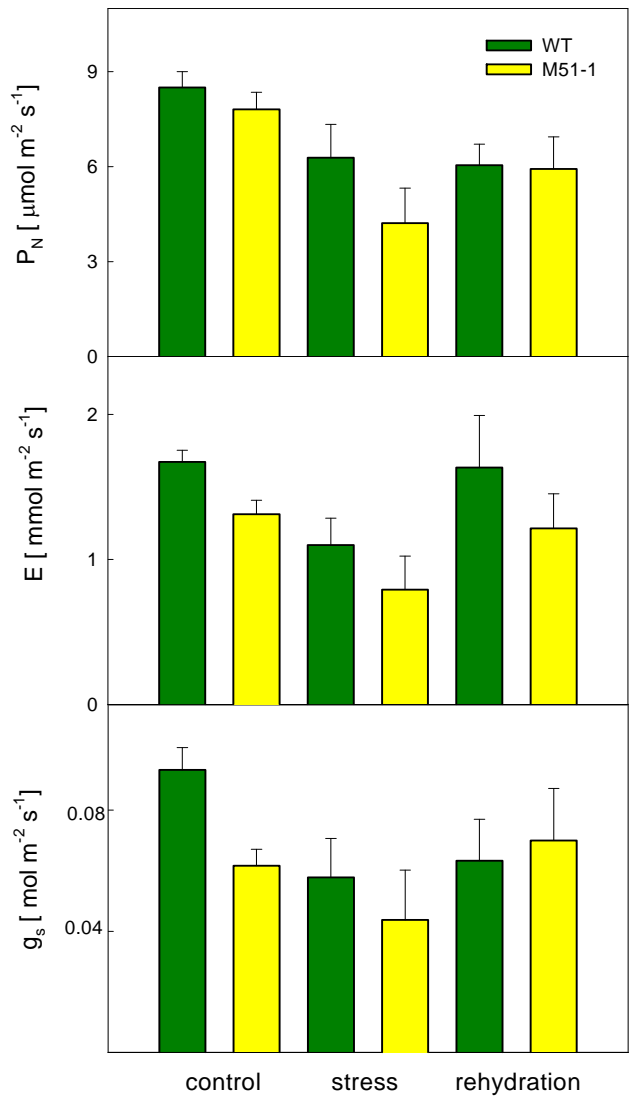

Figure 2. Net photosynthetic rate $\left(\mathbf{P}_{\mathrm{N}}\right)$, transpiration rate $(\mathrm{E})$ and stomatal conductance $\left(\mathrm{g}_{\mathrm{s}}\right)$ in wild type (WT) and transgenic (M51-1) tobacco plants during water stress and rehydration (both lasted 7 days).

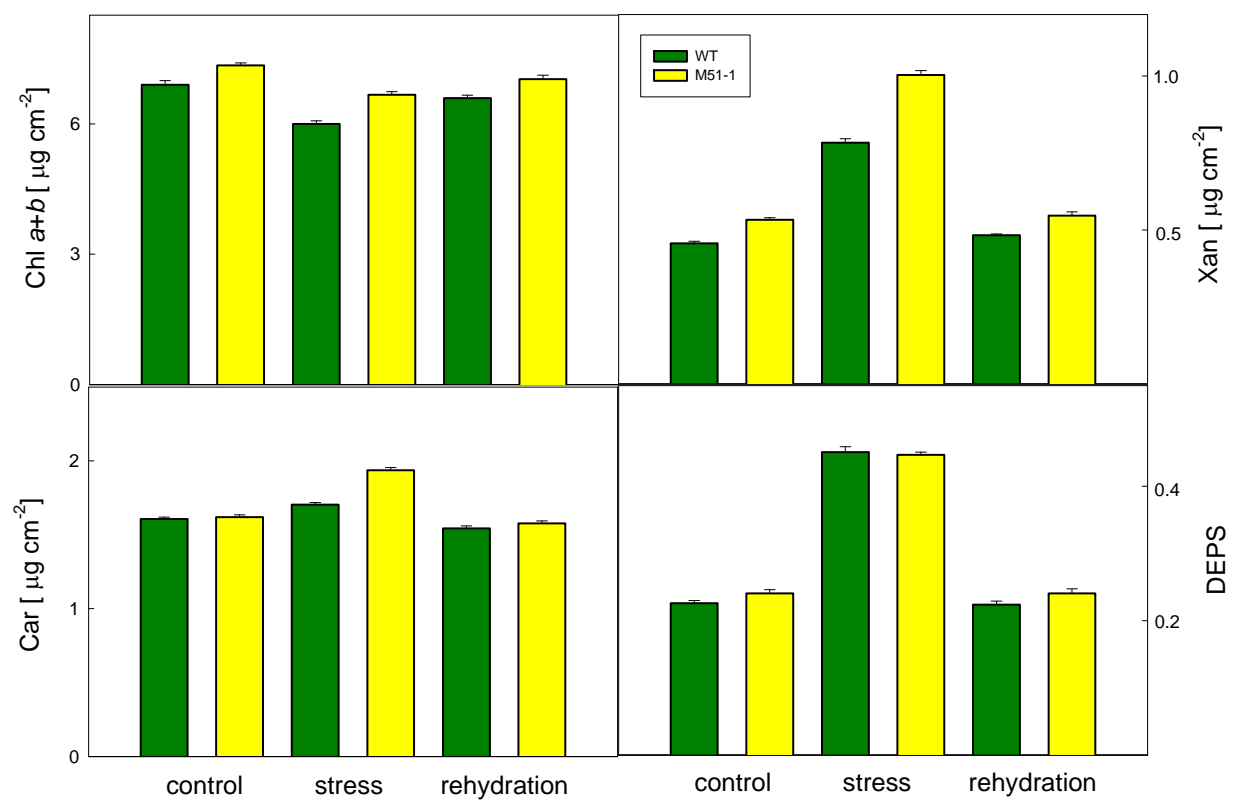

Figure 3. Contents of chlorophylls (Chl $a+b$ ), carotenoids (Car) and xanthophyll cycle pigments (Xan) and Xan degree of deepoxidation (DEPS) in wild type (WT) and transgenic (M51-1) tobacco plants during water stress and rehydration (both lasted 7 days). 
Table 1. Results of statistical evaluation ( $P$ values) of the effects of material $($ WT $\times$ M51-1) under control conditions, 7-d water stress and 7-d rehydration and effect of treatments (control $\times$ stress or rehydration) measured in different materials.

\begin{tabular}{cccccccc}
\hline Parameter & Materials & & \multicolumn{3}{c}{ Treatments } & & \\
\hline & Control & Stress & Rehydration & Stress & & \multicolumn{2}{c}{ Rehydration } \\
\hline & & & WT & M51-1 & WT & M51-1 \\
$\mathrm{P}_{\mathrm{N}}$ & 0.355 & 0.194 & 0.926 & 0.040 & 0.003 & 0.010 & 0.086 \\
$\mathrm{E}$ & 0.007 & 0.317 & 0.329 & 0.003 & 0.021 & 0.881 & 0.656 \\
$\mathrm{~g}_{\mathrm{s}}$ & 0.001 & 0.014 & 0.765 & 0.016 & 0.197 & 0.043 & 0.262 \\
$\mathrm{Chl} a+b$ & 0.017 & 0.003 & 0.019 & 0.002 & 0.002 & 0.061 & 0.044 \\
$\mathrm{Car}$ & 0.530 & 0.001 & 0.252 & 0.007 & 0.001 & 0.041 & 0.137 \\
Xan & 0.001 & 0.001 & 0.007 & $<0.001$ & $<0.001$ & 0.023 & 0.387 \\
DEPS & 0.097 & 0.681 & 0.130 & $<0.001$ & $<0.001$ & 0.770 & 0.971 \\
\hline
\end{tabular}

Table 2. Results of statistical evaluation ( $P$ values) of the effects of material (WT $\times$ M51-1) under control conditions, heat and water stress + heat and effect of treatments (control $\times$ heat or stress + heat) measured in different materials.

\begin{tabular}{|c|c|c|c|c|c|c|c|}
\hline \multirow[t]{3}{*}{ Parameter } & \multirow{3}{*}{$\begin{array}{c}\text { Materials } \\
\text { Control }\end{array}$} & \multicolumn{5}{|c|}{ Treatments } & \\
\hline & & \multirow[t]{2}{*}{ Heat } & \multirow[t]{2}{*}{ Stress + Heat } & \multirow{2}{*}{$\begin{array}{l}\text { Heat } \\
\text { WT }\end{array}$} & \multicolumn{3}{|c|}{ Stress + Heat } \\
\hline & & & & & M51-1 & WT & M51-1 \\
\hline $\mathrm{P}_{\mathrm{N}}$ & 0.831 & 0.380 & 0.008 & 0.012 & 0.012 & $<0.001$ & $<0.001$ \\
\hline E & 0.389 & 0.137 & 0.270 & $<0.001$ & $<0.001$ & $<0.001$ & $<0.001$ \\
\hline $\mathrm{g}_{\mathrm{s}}$ & 0.145 & 0.061 & 0.033 & $<0.001$ & $<0.001$ & $<0.001$ & $<0.001$ \\
\hline Chl $a+b$ & 0.017 & 0.001 & 0.002 & 0.148 & 0.786 & 0.001 & 0.002 \\
\hline Car & 0.530 & 0.336 & 0.001 & 0.530 & 0.336 & 0.009 & $<0.001$ \\
\hline Xan & 0.001 & 0.020 & $<0.001$ & 0.012 & 0.005 & $<0.001$ & $<0.001$ \\
\hline DEPS & 0.097 & 0.240 & 0.026 & 0.002 & 0.031 & $<0.001$ & $<0.001$ \\
\hline
\end{tabular}

\subsection{Response of Transgenic and Wild Type Plants to Heat Stress and Combined Heat and Water Stress}

After heat stress $\left(40^{\circ} \mathrm{C} / 60 \mathrm{~min}\right)$ applied to control or water-stressed plants $\mathrm{P}_{\mathrm{N}}, \mathrm{E}$ and $\mathrm{g}_{\mathrm{s}}$ decreased considerably in both M51-1 and WT plants (Figure 4). These effects were much more pronounced at the combined drought and heat stress than at drought or heat alone. The lowest values of all gas exchange parameters were found in M51-5 plants under combined drought and heat stress. Short-term heat stress alone, however, did not affect significantly pigment contents. The pigment contents, however, were affected by combined heat and water stress in pattern similar to that of water stress alone (Figure 5). Under combined heat and drought, the pigment contents as well as DEPS were higher in M51-1 than in WT plants.

\section{Discussion}

Accumulation of proline during drought was repeatedly reported in many species. The pathways of proline biosynthesis and degradation were recently described [4], but its biological functions have not been fully elucidated yet. The unsolved question is whether proline accumulation is a sign of stress tolerance or only consequence of the stress (for review see [12]). The reply to this question was searched by determination of changes in proline content during different stresses, by application of proline with the aim to ameliorate negative effects of stress (for review see e.g. $[3,12]$ ) and recently by using transgenic plants with increased endogenous proline content. The last approach has been based either on increased of proline biosynthesis achieved by over-expression of $P 5 C S$ gene [16-18] or on decrease of proline degradation by re- 
pression of $P D H$ genes [9]. In addition, it has been found that antisense P5CS transgenic Arabidopsis plants, showing significantly lower proline accumulation than respective wild type, were hypersensitive to osmotic stress [19].

General feature of transgenic plants over-expressing P5CS gene was high accumulation of proline, especially under stress conditions. In indica rice accumulation of proline was accompanied by better biomass production and growth performance under drought or salt stress $[18,20]$. It was rather surprising that in sugarcane, Vigna aconitifolia and tobacco the increase in proline accumulation was not accompanied by markedly higher osmotic adjustment in transgenic plants than in respective WT plants $[15,20,21]$.

In our experiments, transgenic tobacco plants M51-1 had a little lower $\mathrm{E}$ and $\mathrm{g}_{\mathrm{s}}$ that WT plants under sufficient water supply, which might be caused by slightly higher ABA content in M51-1 than in the WT plants. Lower E might led to lower water consumption, more conservative water use and better growth as observed by Molinari et al. [20], Vendruscolo et al. [21] and Dobra et al. [15].

Chl content was slightly higher in M51-1 than in WT plants. Due to the higher Chl content but lower $\mathrm{g}_{\mathrm{s}}$ in M51-1 than in WT, $\mathrm{P}_{\mathrm{N}}$ was similar in both genotypes. Due to similar $\mathrm{P}_{\mathrm{N}}$ and lower E, WUE was higher in M51-1 than in WT plants. This can be a positive feature of M51-1 plants leading to better utilization of water sources. On the other hand, transpiration efficiency (measured as accumulation of biomass per amount of water transpired) in chickpea plants was similar in transgenic plants with high proline content to that in WT plants [22].

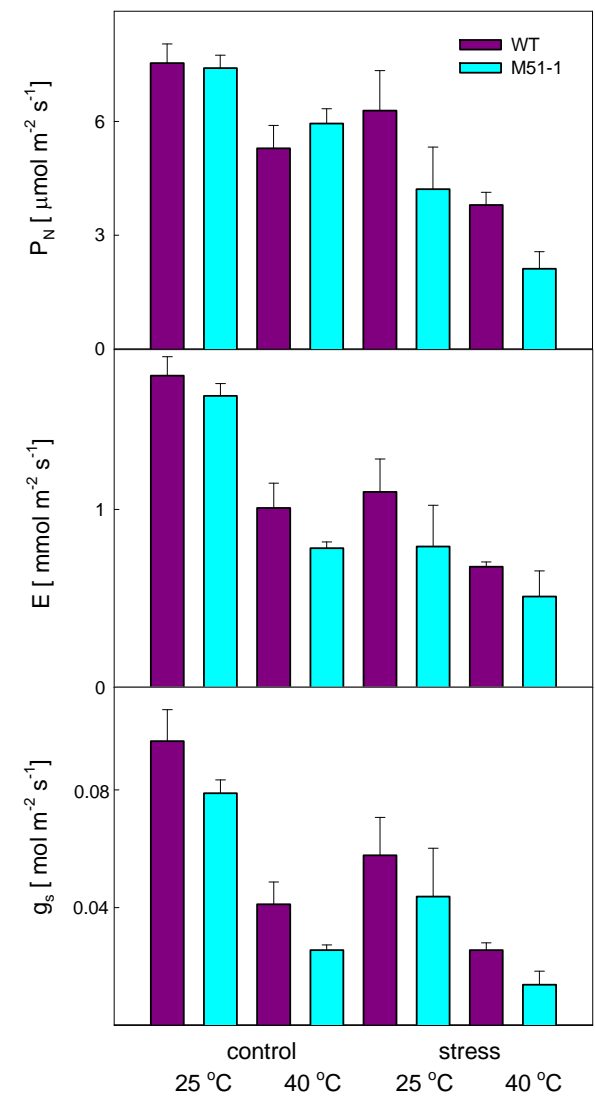

Figure 4. Net photosynthetic rate $\left(P_{N}\right)$, transpiration rate $(E)$ and stomatal conductance $\left(\mathrm{g}_{\mathrm{s}}\right)$ in wild type (WT) and transgenic (M51-1) tobacco plants after heat shock $\left(40^{\circ} \mathrm{C} / 60 \mathrm{~min}\right)$ imposed to plants sufficiently supplied with water or to water-stressed plants.

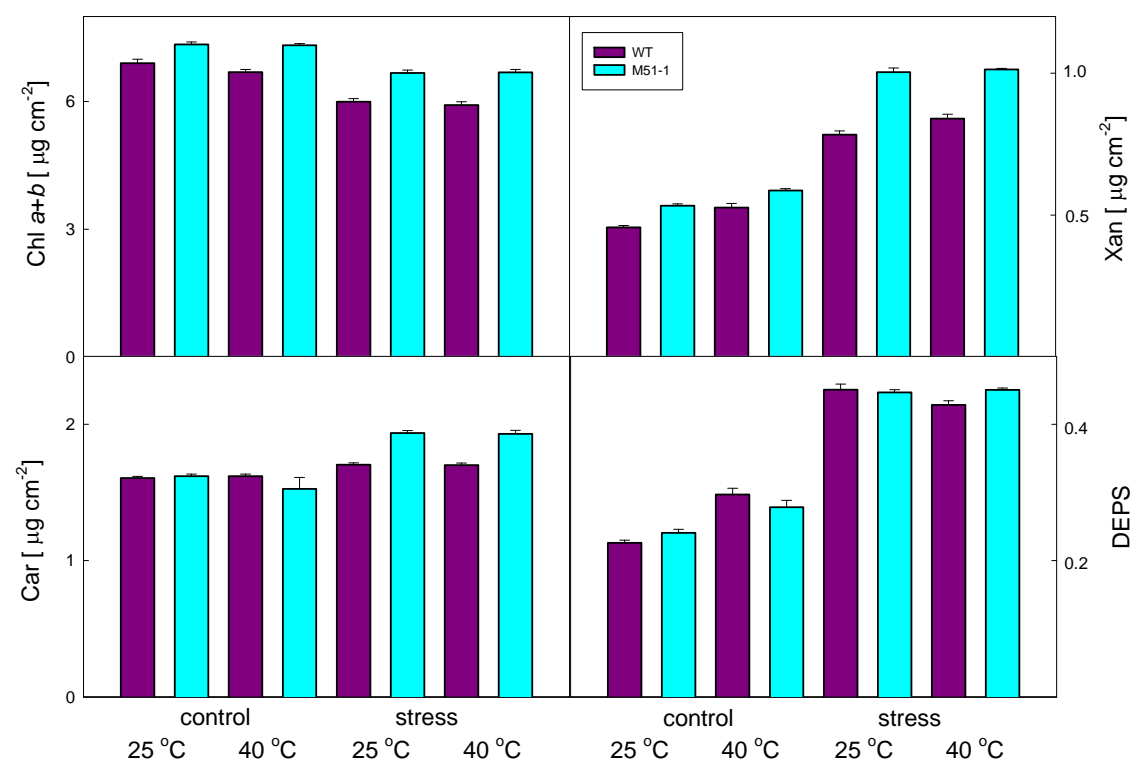

Figure 5. Contents of chlorophylls (Chl $a+b)$, carotenoids (Car) and xanthophyll cycle pigments (Xan) and Xan degree of deepoxidation (DEPS) in wild type (WT) and transgenic (M51-1) tobacco plants after heat shock (40 $\left.{ }^{\circ} \mathrm{C} / 60 \mathrm{~min}\right) \mathrm{imposed}$ to plants sufficiently supplied with water or to water-stressed plants. 
However, no marked difference in the responses to water stress, including decrease in $\mathrm{E}, \mathrm{g}_{\mathrm{s}}, \mathrm{P}_{\mathrm{N}}$ and Chl content and increase in Xan content and DEPS, was observed between the genotypes. The same holds for the recovery after water stress. When $P 5 C S$ gene was introduced under stress-inducible promotor, Chl content and variable to maximum $\mathrm{Chl}$ fluorescence ratio $\left(\mathrm{F}_{\mathrm{v}} / \mathrm{F}_{\mathrm{m}}\right)$ in transgenic and WT sugarcane plants did not differ under sufficient water supply but, in contrast to our results, these characteristics remained higher in transgenic plants that in WT plants under water stress [20]. During simultaneous drought and heat stress, dissociation of the oxygen-evolving complex was bypassed by proline feeding electrons into photosystem 2, maintaining the acceptable NADPH level in transgenic soybean plants [23]. Under drought stress, the cumulative daily transpiration was higher only in some lines of transgenic chickpea plants than that in WT plants. Also $g_{s}$ in these transgenic chickpea plants was slightly higher than of WT at both control and stress conditions [22].

Short-term heat stress affected only gas exchange parameters but not pigment contents. Application of heat stress to previously water-stressed plants led to further decrease in $\mathrm{E}, \mathrm{g}_{\mathrm{s}}$ and $\mathrm{P}_{\mathrm{N}}$. Similar results were recently mentioned in two pepper cultivars [24] and Ceratonia siliqua [25]. Our data indicate only relatively minor differences between M51-1 and WT in responses to heat or combined stresses.

All the above-mentioned results did not prove clear correlation between proline accumulation and stress tolerance. However, in our experiments, the induced stresses were rather mild than severe. Maybe, that under severe stress, the proline plays more important role, especially as protectant against oxidative stress as suggested, e.g., Molinari et al. [20]) and Vendruscolo et al. [21].

\section{Conclusions}

The increased content of proline in transgenic tobacco plants M51-1 was accompanied by slightly lower E and $\mathrm{g}_{\mathrm{s}}$ and slightly higher $\mathrm{Chl}$ and Xan content under sufficient water supply, which might suggest more conservative water regime in these transgenic plants than in respective WT plants. The changes of all parameters induced by mild water stress or/and heat shock reflect more similarities than differences in response of M51-1 and WT tobacco plants. Therefore, the clear correlation between proline content and stress tolerance was not proved in our experiments.

\section{Acknowledgements}

The authors are grateful to Dr. Jozef Gubis, Res. Inst. Plant Prod., Piestany, Slovakia, for providing plant material. This work was supported by the Grant Agency of the
Czech Republic, project No. 522/09/2058.

\section{REFERENCES}

[1] A. Ogawa and A. Yamauchi, "Root Osmotic Adjustment under Osmotic Stress in Maize Seedlings. 2. Mode of Accumulation of Several Solutes for Osmotic Adustment in the Root," Plant Production Sciences, Vol. 9, No. 1, 2006, pp. 39-46. doi:10.1626/pps.9.39

[2] D. J. Walker, P. Romero and E. Correal, "Cold Tolerance, Water Relations and Accumulation of Osmolytes in Bituminaria bituminosa," Biologia Plantarum, Vol. 54, No. 2, 2010, pp. 293-298. doi:10.1007/s10535-010-0051-x

[3] B. Heuer, "Osmoregulatory Role of Proline in Plants Exposed to Environmental Stresses," In: M. Pessarakli, Ed., Handbook of Plant and Crop Stress, 2nd Edition, Marcel Dekker, New York, 1999, pp. 675-695.

[4] L. Szabados and A, Savouré, "Proline: A Multifunctional Amino Acid," Trends in Plant Science, Vol. 15, No. 2, 2010, pp. 89-97. doi:10.1016/j.tplants.2009.11.009

[5] P. D. Hare, W. A. Cress, "Metabolic Implications of StressInduced Proline Accumulation in Plants," Plant Growth Regulation, Vol. 21, No. 2, 1997, pp. 79-102. doi:10.1023/A:1005703923347

[6] M. Thippeswamy, P. Chandraobulreddy, B. Sinilal, M. Shiva Kumar and Chinta Sudhakar, "Proline Accumulation and the Expression of $\Delta^{1}$-Pyrroline-5-Carboxylate Synthetase in Two Safflower Cultivars," Biologia Plantarum, Vol. 54, No. 2, 2010, pp. 386-390. doi:10.1007/s10535-010-0070-7

[7] P. B. Kavi Kishor, S. Sangam, R. N. Amrutha, P. S. Laxmi, K. R. Naidu, K. R. S. S. Rao, S. Rao, K. J. Reddy, P. Theriappan and N. Sreenivasulu, "Regulation of Proline Biosynthesis, Degradation, Uptake and Transport in Higher Plants: Its Implications in Plant Growth and Abiotic Stress Tolerance," Current Science, Vol. 88, No. 3, 2005, pp. 424-438.

[8] Y. Jung, J. Park, Y. Choi, J.-G. Yang, D. Kim, B.-G. Kim, K. Roh, D.-H. Lee, C.-K. Auh and S. Lee, "Expression" Analysis of Proline-Metabolism Genes from Halophyte Arabis stelleri under Osmotic Stress Conditions," Journal of Integrative Plant Biology, Vol. 52, No. 10, 2010, pp. 891-903. doi:10.1111/j.1744-7909.2010.00990.x

[9] G. Miller, H. Stein, A. Honig, Y. Kapulnik and A. Zilberstein, "Responsive Modes of Medicago sativa Proline Dehydrogenase Genes during Salt Stress and Recovery Dictate Free Proline Accumulation," Planta, Vol. 222, No. 1, 2005, pp. 70-79.

[10] C. O. Silva-Ortega, A. E. Ochoa-Alfaro, J. A. ReyesAgüero, G. A. Aguado-Santacruz and J. F. Jiménez-Bremont, "Salt Stress Increases the Expression of P5CS Gene and Induces Proline Accumulation in Cactus Pear," Plant Physiology and Biochemistry, Vol. 46, No. 1, 2008, pp. 82-92. doi:10.1016/j.plaphy.2007.10.011

[11] G. Szekely, E. Abraham, A. Cselo, G. Rigo, L. Zsigmond, J. Csiszar, F. Ayaydin, N. Strizhov, J. Jasik, E. Schmelzer, C. Koncz and L. Szabados, "Duplicated P5CS Genes of 
Arabidopsis Play Distinct Roles in Stress Regulation and Developmental Control of Proline Biosynthesis," Plant Journal, Vol. 53, No. 1, 2008, pp. 11-28. doi:10.1111/j.1365-313X.2007.03318.X

[12] M. Ashraf and M. R. Foodlad, "Roles of Glycine Betaine and Proline in Improving Plant Abiotic Stress Resistance," Environmental and Experimental Botany, Vol. 59, 2007, pp. 206-216. doi:10.1016/i.envexpbot.2005.12.006

[13] S. Lutts, J. M. Kinet and J. Bouharmont, "Effects of Salt Stress on Growth, Mineral Nutrition and Proline Accumulation in Relation to Osmotic Adjustment in Rice (Oryza sativa L.) Cultivars Differing in Salinity Resistance," Plant Growth Regulation, Vol. 19, No. 2, 1996, pp. 207-218. doi:10.1007/BF00037793

[14] J. Gubis, R. Vankova, V. Cervena, M. Dragounova, M. Hudcovicova, H. Lichtnerovia, T. Dokoupil and Z. Jurekova, "Transformed Tobacco Plants with Increased Tolerance to Drought," South African Journal of Botany, Vol. 73. No. 4, 2007, pp. 505-511.

[15] J. Dobra, V. Motyka, P. Dobrev, J. Malbeck, I. T. Prasil, D. Haisel, A. Gaudinova, M. Havlova, J. Gubis and R. Vankova, "Comparison of Hormonal Responses to Heat, Drought and Combined Stress in Tobacco Plants with Elevated Proline Content," Journal of Plant Physiology, Vol. 167, No. 16, 2010, pp. 1360-1370. doi:10.1016/j.jplph.2010.05.013

[16] P. B. Kavi Kishor, Z. Hong, G.-H. Miao, C. A. Hu and D. P. S. Verma, "Overexpression of $\Delta^{1}$-Pyrroline-5-Carboxylase Synthetase Increases Proline Production and Confers Osmotolerance in Transgenic Plants," Plant Physiology, Vol. 108, No. 4, 1995, pp. 1387-1394.

[17] R. Dibax, C. Deschamps, J. C. Bespakhok Filho, L. G. E. Vieira, H. B. C. Milinari, M. K. F. De Campos and M. Quorin, "Organogenesis and Agrobacterium tumefaciensMediated Transformation of Eucalyptus saligna with P5CS Gene," Biologia Plantarum, Vol. 54, No. 1, 2010, pp. 6-12. doi:10.1007/s10535-010-0002-6

[18] V. Kumar, V. Shriram, P. B. Kavi Kishor, N. Jawali and M. G. Shitole, "Enhanced Proline Accumulation and Salt Stress Tolerance of Transgenic Indica Rice by over-Expressing P5CSF129A Gene," Plant Biotechnology Reports, Vol. 4, No. 1, 2010, pp. 37-48.
[19] T. Nanjo, M. Kobayashi, Y. Yoshiba, Y. Sanada, K. Wada, H. Tsukaya, Y. Kakubari, K. Yamaguchi-Shinozaki and K. Shinozaki, "Biological Functions of Proline in Morphogenesis and Osmotolerance Revealed in Antisense Transgenic Arabidopsis," The Plant Journal, Vol. 18, No. 2, 1999, pp. 185-193. doi:10.1046/j.1365-313X.1999.00438.x

[20] H. B. C. Molinari, C. J. Marur, E. Daros, M. K. Freitas de Campos, J. F. R. Portela de Carvalho, J. C. B. Filho, L. F. P. Pereira and E. L. G. Vieira, "Evaluation of the StressInducible Production of Proline in Transgenic Sugarcane (Saccharum spp.): Osmotic Adjustment, Chlorophyll Fluorescence and Oxidative Stress," Physiologia Plantarum, Vol. 130, No. 2, 2007, pp. 218-229. doi:10.1111/j.1399-3054.2007.00909.x

[21] E. C. G. Vendruscolo, I. Schuster, M. Pileggi, C. A. Scapim, H. B. C. Molinari, C. J. Marur and E. L. G. Vieira, "Stress-Induced Synthesis of Proline Confers Tolerance to Water deficit in Transgenic Wheat," Journal of Plant Physiology, Vol. 164, No. 10, 2007, 1367-1376. doi:10.1016/i.jplph.2007.05.001

[22] P. Bhatnagar-Mathur, V. Vadez, M. J. Devi, M. Lavanya, G. Vani and K. K. Sharma, "Genetic Engineering of Chickpea (Cicer arietinum L.) with the P5CSF129A Gene for Osmoregulation with Implications on Drought Tolerance," Molecular Breeding, Vol. 23, No. 4, 2009, pp. 591-606. doi:10.1007/s11032-009-9258-y

[23] J. A. De Ronde, W. A. Cress, G. H. J. Kruger, R. J. Streasser, J. Van Staden, "Photosynthetic Response of Transgenic Soybean Plants, Containing an Arabidopsis P5CR Gene, during Heat and Drought Stress," Journal of Plant Physiology, Vol. 161, No. 11, 2004, pp. 1211-1224. doi:10.1016/j.jplph.2004.01.014

[24] W. H. Hu, Y. A. Xiao, J. J. Zeng and X. H. Hu, "Photosynthesis, Respiration and Antioxidative Enzymes in Pepper Leaves under Drought and Heat Stresses," Biologia Plantarum, Vol. 54, No. 4, 2010, 761-765.

[25] M. L. Osório, J. Osório, A. C. Vieira, S. Gonçalves and A. Romano, "Influence of Enhanced Temperature on Photosynthesis, Photooxidative Damage, and Antioxidant Strategies in Ceratonia siliqua L. Seedlings Subjected to Water Deficit and Rewatering," Photosynthetica, Vol. 49, No. 1, 2011, 3-12. 